\title{
Comparing investment projects of innovative developing strategies of municipalities, based on a set of indicators
}

\author{
Tatiana Saurenko ${ }^{1}$, Vladimir Anisimov ${ }^{2}$, Evgeniy Anisimov ${ }^{1}$ and Anastasia Levina ${ }^{2, *}$ \\ ${ }^{1}$ Peoples Friendship University of Russia (RUDN University), 6 Miklukho-Maklaya St, 117198, \\ Moscow, Russia \\ ${ }^{2}$ Peter the Great St.Petersburg Polytechnic University, Polytechnicheskaya, 29, 195251, \\ St. Petersburg, Russia
}

\begin{abstract}
A method of comparison by a set of indicators which show the quality of investment projects and embody innovative policy of developing municipal entities is proposed. The method is based on establishing preferences for individual quality indicators of projects in accordance with the principle of maximum uncertainty (entropy) and representing their aggregate in the form of a scalar function as an argument of the vector.
\end{abstract}

\section{Introduction}

Long-term socio-economic development of the country and provision of quality life to citizens in the modern era at this stage largely depends on the formation and implementation of rational innovation policy for the development of municipalities. The realization of this policy objectively requires an established mechanism to attract investments for innovation activities from organizations that work in tandem with local Governments.

One of the main forms of organizing innovation activities of local government organizations is the organization of development and implementation of innovative projects; funding is attracted into this sphere in the form of suitable investment projects. The investor on declining the current use of benefits, expects to obtain certain benefits regarding his/her area of interest in the future. Therefore, the consumer values are withdrawn and are invested in the corresponding innovation projects. Through the realization of these projects, the values are returned to the investors in the form of positive effects in the economic, scientific, technical, social, environmental, political and others areas of interest.

In general, standard effects reflecting the aim of investors in economic spheres are mainly commercial effects (the profit in the market is provided by sales of generated innovation, the payback period, etc.) and the effects characterizing the influence of innovation on the growth of economic potential (increase in labor productivity, yield, the

\footnotetext{
* Corresponding author : alyovina@gmail.com
} 
competitiveness of manufactured goods and services, the increase in budgetary allocations, reducing the duration of capital construction, etc.).

In the sphere of technical sciences and technology, following are identified as positive effects:

-increase in relative contribution of advanced technologies,

-increase in technical efficiency of the manufactured products,

-increase in the impact of mechanization and automation on production, etc.

The effects that are associated with society are:

-increase in job opportunities,

-rise in salary income,

-improvement in the conditions of work place and leisure time,

-increase in social benefits,

-satisfying the social and spiritual needs of the population, etc.

In ecology following are the main effects:

-minimization of harmful environmental emissions,

-reducing waste and increasing production ergonomics,

-increasing environmental safety of manufactured products, etc.

The developed, advanced methods and computational tools for investment design and analysis of investment projects are based on the fact that in market economy, the investment objective is for the investor to obtain the maximum possible profit from the invested resources in the shortest possible time. In this case, preference is given to projects that can bring about the fastest possible maximum profit.

It is overlooked that what is tempting in short term duration can be destructive in the long term. It is not taken into consideration that the aim of innovation and its investment projects might not be attainment of super profits, but, for example, it could be the improvement of living standards, human welfare or public health. This approach does not correspond with the modern scientific, technical and innovation policies of the government.

The urge to overcome this discrepancy lead to development of a method for justifying investment decisions and their alignment with the targets of innovation policy. In addition, various objectives of the policy encouraged a comparative evaluation of investment projects on a set of indicators. Generally, this evaluation is nontrivial and has a rather complicated problem [1-11]. This article includes one of the ways to solve the problem which is based on aggregation of indicators to a generalized index.

\section{Description of the method}

From a mathematical point of view, the aggregation of indicators to a generalized index is the formation of a scalar function of the vector argument for the selected set of project quality indicators:

$$
q(j)=q\left[w_{i}(j)\right], \quad j=\overline{1, J}, \quad i=\overline{1, I},
$$

where,

$\mathrm{J}$ - number of investment projects to be compared;

$\mathrm{j}$ - identifier of the type of investment project;

I- the number of indicators that characterize the comparison of options for investment projects;

$\mathrm{i}$ - identifier of the quality indicator;

wi $(j)$ - vector evaluation of $i$ and $j$.

The generalized indicator allows to arrange the alternating values in terms of $q(j)$, and to select the best (as in the maximum criterion for the indicator) option. 
The function $\mathrm{q}(\mathrm{j})$, is determined by the modeling of contribution of each indicator in to a generalized indicator. Usually, additive (2) or multiplicative (3) functions are used:

$$
\begin{gathered}
q(j)=\sum_{i=1}^{I} P_{i} S_{i}(j), \quad j=\overline{1, J} \\
q(j)=1-\prod_{i=1}^{I}\left[1-P_{i} S_{i}(j)\right], \quad j=\overline{1, J}
\end{gathered}
$$

Where $\operatorname{Si}(j)$ - the evaluation of vector components $i(i=1,2, \ldots, I)$ and $j$ is reduced to a single scale;

Pi-coefficients of comparative importance (weighting factors) corresponding to individual indicators.

In order to determine the value of $\mathrm{Si}(\mathrm{j})$, it is necessary to choose a standard project. As a reference, it is advisable to use a conventional investment project that has the highest values of the quality indicators of the projects to be compared, that is

$$
w_{i}^{*}(j)=\max _{i, j} w_{i}(j), i=\overline{1, I}, j=\overline{1, J}
$$

Every investment project considered to be standardized are characterized by

$$
S_{i j}^{*}=\frac{w_{i}(j)}{w_{i}^{*}(j)}, \quad i=\overline{1, I}, j=\overline{1, J}
$$

Introducing the parameters dij, as

$$
d_{i j}=\left\{\begin{array}{l}
1, \text { if the increase in } S_{i j}^{*} \text { leads to increase in project preferences, } \\
0-- \text { otherwise. }
\end{array}\right.
$$

Then each investment projects can be characterized by the values

$$
S_{i}(j) \quad i=1,2, \ldots, I, \quad j=1,2, \ldots, J
$$

So that,

$$
S_{i}(j)=\left\{\begin{array}{c}
S^{*}{ }_{i j} \quad \text { when } d_{i j}=1 \\
1-S_{i j}^{*} \text { when } d_{i j}=0
\end{array}\right.
$$

In the given method of reducing the quality indicators of projects to a single scale, firstly, the generalized indicator q (j) becomes dimensionless, in addition the individual indicators can have various measurements and, secondly, the fulfillment of the condition $0 \leq q(j) \leq 1$, is necessary for the accuracy of the relation (3).

The specialty of the proposed method for comparing investment projects is the determination of numerical values of the coefficients $\mathrm{Pi}(\mathrm{i}=1,2, \ldots, \mathrm{I})$ pertaining to relative importance of the individual indicators. From experience it can be said that while managing the investment projects, the decision-maker usually does not have clarity in the choice of quality of one project over the other.

The above situation acquires special significance at the early stages of project evaluation. In that case, principle of maximum uncertainty can be used to determine the coefficients of relative importance of individual quality indicators. The expediency of its 
application is explained by the fact that in the analysis of investment projects, the available information does not allow:

1) to determine the exact value of relative importance of an indicator in all possible conditions for the implementation of the investment project;

2) to accurately determine the law of probability distribution of relative importance of indicators.

Therefore, out of all possible values of probability distribution it is important to choose the most stable coefficient. This is the distribution law, characterized by the maximum value measured by entropic uncertainty, which remained after using all the objective information available to the person making the decision [12-14].This law of probability distribution is based on minimum speculation. Therefore, it is most objective in the given situation.

From experience in management of investment projects that are realizing the innovative policy of the development of municipalities, the practical possibilities for analyzing the weight factors $\mathrm{Pi}, \mathrm{i}=1,2, \ldots, \mathrm{I}$, are limited to the comparison of pairs. After comparison, linear order relations can establish multiple $P=\left\{P_{i}\right\}, \quad i=1,2, \ldots, I$ set of coefficients. Therefore, in reality, the determination of numerical values $P i \mathrm{i}=1,2, \ldots$, I creates a method for transforming preferences, given in the form of relations considering corresponding quantitative estimates.

We can solve the problem of determining the weight coefficients of the quality indicators of alternative investment projects by using the models proposed by Fishburn to obtain a priori of probability of quantitative estimates, that does not contradict to the linear system. [15-18].

The expediency of using such models is due to the fact that establishing relations of order on a set $P=\left\{P_{i}\right\}, \quad i=1,2, \ldots, I$ of coefficients is one of the easiest operations of analyzing the alternative projects corresponding to the real activity of investors.

It can be shown that if the different characteristics of each project are equal, then the uniform distribution has the greatest entropy. Taking this into account, the quantitiesPii = $1,2, \ldots, \mathrm{I}$ are determined by the formula

$$
P_{i}=\frac{\sum_{j=1}^{J} S_{i}(j)}{\sum_{i=1}^{I} \sum_{j=1}^{J} S_{i}(j)}, \quad i=1,2, \ldots, I .
$$

When determining a set for elements $P=\left\{P_{i}\right\}, \quad i=1,2, \ldots, I$ a simple linear order relation $P_{1} \geq P_{2} \geq \ldots \geq P_{I}$, the weighting factors are calculated by the formula

$$
P_{i}=\frac{2(I-i+1)}{I(I+1)}, \quad i=1,2, \ldots, I .
$$

When $\mathrm{I}=5$, we get:

$P_{1}=0.333, P_{2}=0.267, P_{3}=0.200, P_{1}=0.333, P_{2}=0.267, P_{3}=0.200$, $P_{4}=0.133, P_{5}=0.067 \quad P_{4}=0.133, P_{5}=0.067$

When determining a set for elements $P=\left\{P_{i}\right\}, \quad i=1,2, \ldots, I$ in a relation of strict order $P_{1}>P_{2}>\ldots>P_{I}, P_{i}, \quad i=1,2, \ldots, I$ weight coefficients are calculated by the formula

$$
P_{i}=\frac{I-i+2}{I 2^{i}}, \quad i=1,2, \ldots, I .
$$


When $\mathrm{I}=5$ :

$$
\begin{aligned}
& P_{1}=0.600, P_{2}=0.250, P_{3}=0.100, \\
& P_{4}=0.038, P_{5}=0.012 .
\end{aligned}
$$

While establishing a set for elements $P=\left\{P_{i}\right\}, \quad i=1,2, \ldots, I$ a relation of strict linear order $P_{i} \geq \sum_{n=i+1}^{I} P_{n}, \quad i=1,2, \ldots, I$, then point estimations of weighting factors are determined by the formula

$$
P_{i}=\frac{2^{I-i}}{2^{I}-1}, \quad i=1,2, \ldots, I .
$$

For I=5 : $P_{1}=0.516, P_{2}=0.258, P_{3}=0.129, P_{4}=0.065, P_{5}=0.032$.

\section{Results}

In general, the proposed approach ensures the transformation of vector indicators of investment projects into scalar indices equivalent to them. This gives unambiguous results of their comparison.

\section{Conclusion}

The main feature of the proposed approach is that it makes maximum use of information that is actually available to the person who makes a decision about the advantages of a project over others. Moreover, subjective information added to them is minimized. This ensures the maximum level of objectivity of the evaluations obtained in the current information situation.

The proposed method for comparing investment projects by the system of indicators of quality, characterize the aimed compliance of these projects in correspondence with innovation policy. This can be used in decision making support systems to attract investments in innovation performance of local government bodies corresponding to municipal entities. The method of evaluation of investment projects is well aligned with the accepted system of their examination. Based on the definition of relative importance of individual indicators, the principle of maximum entropy provides a certain objective to the results of quality assessment of investment projects, taking into account the uncertainty of planning in the early stages of innovative developing strategies of municipalities.

\section{References}

1. O.Yu. Iliashenko, A.I. Levina, A.D. Borremans, Proc. of the 29th IBIMA Conf., 11771186 (2017)

2. G.Y. Silkina, Proc. of the 29th IBIMA Conf., 1165-1176 (2017)

3. I.V. Ilin, O.V. Kalinina, A.I. Levina, O.Yu. Iliashenko, MATEC Web of Conferences, 05028 (2016)

4. I.V. Ilin, A.I. Levina, O.Yu. Iliashenko, MATEC Web of Conferences 106, 0806 (2017)

5. A.B. Anisiforov, A.S. Dubgorn, Proc. of the 29th IBIMA Conf., 2920-2930 (2017) 
6. A.V. Flegontov, A. Chernykh, P. Klykov, Int. Conf. "Stability and Control Processes" in Memory of V.I. Zubov (SCP), 558-559 (2015)

7. V. Anisimov, E. Anisimov, M. Sonkin. Int. Jour. of App. Eng. Res. 10(17), 3812738132 (2015)

8. A.R. Bril, O.V. Kalinina, I.V. Ilin, MATEC Web of Conferences 106, 08010 (2017)

9. A.V. Izotov, O.V. Rostova, Proc. of the 29th Int. Bus. Inf. Man. Ass. Conf., 1812-1822 (2017)

10. V.G. Anisimov, E.G. Anisimov, T.N. Saurenko, M.A. Sonkin, Jour. of Phys.: Conf. Ser. 803, 012006 (2017)

11. A.R. Bril, O.V. Kalinina, I.V. Ilin, A.S. Dubgorn, O.Y. Iliashenko. Proc. of 2017 20th IEEE Inter. Conf. on Soft Comp. and Meas., SCM 2017 7970692, 692-693 (2017)

12. J.W. Gibbs, Elementary principles in statistical mechanics (Longmans N.Y.,1902)

13. E.T. Jaynes, Phys. Rev. 106, 620-630 (1957)

14. E.T. Jaynes, Ann. Rev. Phys. Chem. 31, 579-601 (1980)

15. P.S. Fishburn, Decision and value theory (Wiley, New York, 1964)

16. P.S. Fishburn, Ann. Math. Statistics 40, 1419-1429 (1969)

17. L.N.Nikolova, D. G. Rodionov, M.A.Bahauovna, International Journal of Economics and Financial 6(2), 246-252 (2016)

18. A. Mottaeva MATEC Web of Conferences, 106, 08071 (2017) https://doi.org/10.1051/matecconf/201710608071 